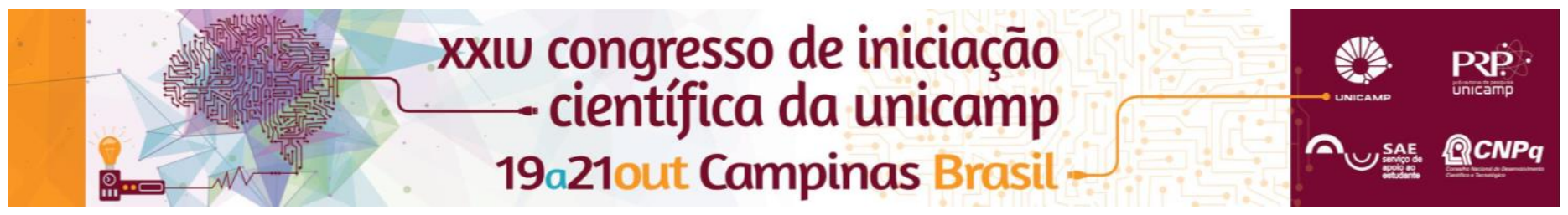

\title{
Ensaio hidrodinâmico em sistema combinado anaeróbio-aeróbio com recirculação interna.
}

\section{Cláudia N. Paltronieri, Edson A. A. Nour, Mariana L. Adário, Raphael F. Duarte*.}

\section{Resumo}

Fez-se um estudo hidrodinâmco com o objetivo de analisar a diferença entre o tempo de detenção hidráulica teórico e o real e analisar o tipo de regime que ocorre no reator operado de forma a alcançar a concentração limite para inibição da biomassa anaeróbia, e posterior adoção da recirculação interna do efluente tratado para alcançar a reversão da inibição desta biomassa.

\section{Palavras-chave}

sistemas combinados anaeróbio-aeróbio, hidrodinâmica de reatores, tratamento de efluentes..

\section{Introdução}

A hidrodinâmica dos reatores pode influenciar na velocidade das reações biológicas por meio de alterações na taxa de transferência de massa e a distribuição das reações. Além disso, o traçador ideal é facilmente miscível no liquido e não altera significantemente as características do escoamento, em contrapartida os curtos-circuitos hidráulicos, caminhos preferenciais e zonas mortas podem prejudicar a eficiência dos reatores devido ao aumento do tempo de detenção hidráulica. Assim, a fim de trazer vantagens, a combinação de processos anaeróbio/aeróbio foi feita, já que o anaeróbio possui baixa produção de sólidos (lodo) e utiliza de uma tecnologia simples e de baixo consumo energético e custo operacional, porém o efluente tratado ainda contém um residual importante de carga orgânica. Já o processo aeróbio, o qual apresenta maior custo de operação e produção de lodo, atua na remoção deste residual. A combinação de processos minimiza custos de operação e manutenção.

\section{Traçador $\mathrm{NaCl}$ :}

\section{Resultados e Discussão}

Foi injetado $10 \mathrm{~mL}$ de uma solução de $40 \mathrm{~g} / \mathrm{L}$ de $\mathrm{NaCl}$ no reator.

Figura 1: Concentração x Tempo do Nacl no reator

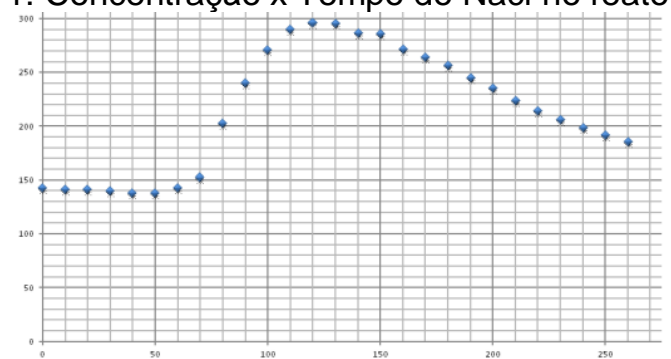

Foi observado que o tempo de detenção hidráulica deu acima do esperado de 55 horas, além de observar-se o "efeito de cauda", onde a provável causa disso seja a presença de caminhos preferenciais ou zonas de estagnação.

\section{Traçador Eosina Y:}

Foram mantidos os mesmo padrões utilizados no traçador $\mathrm{NaCl}$.

Figura 2 : Concentração $\times$ Tempo de Eosina $Y$ com recirculação (água como substrato):

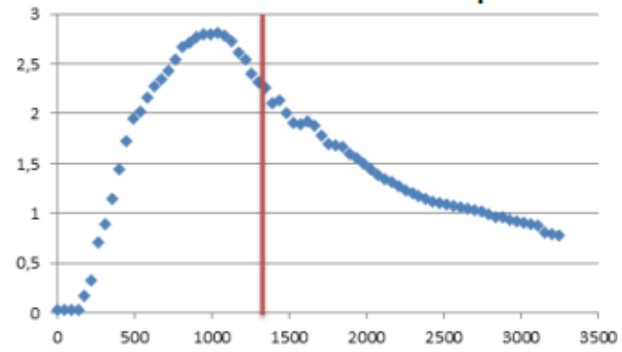

Figura 3: Concentração $\mathrm{x}$ Tempo de Eosina $\mathrm{Y}$ com recirculação (esgoto como substrato)

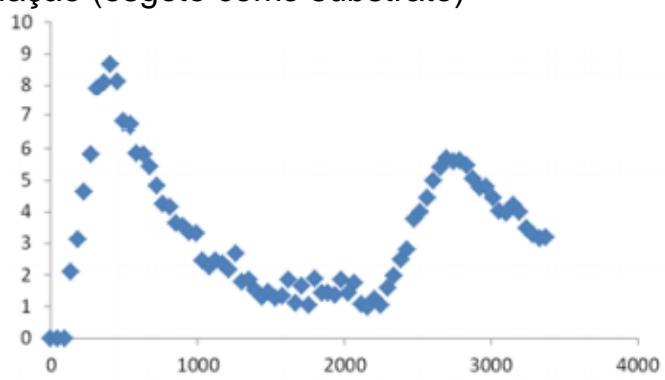

Observou-se pela figura 3 que ocorreu dois picos devido a presença de zonas mortas no reator em questão.

\section{Conclusões}

Verificou-se que o melhor traçador para a análise do reator em questão seria o Eosina $Y$ por apresentar um efeito de cauda muito menor e, apesar da presença de zonas mortas ou caminhos preferenciais, houve uma atenuação do pico. De acordo com os resultados, o reator possui um fluxo disperso.

\section{Agradecimentos}

Ao PIBIC/ SAE-UNICAMP pelo investimento financeiro. Ao meu orientador Edson A. A. Nour, pelo empenho dedicado ao trabalho e ao trabalho junto com as mestrandas Mariana L. Adário e Claudia N. Paltronieri que tanto me ajudaram em todas as pesquisas e aos meus pais e amigos que me deram incentivo e apoio.

LEVENSPIEL, O.Engenharia das Reações Químicas.3 ed.São Paulo Ed Edgard Blüche Ltda, 563 p. 2000.

CASTRO, F.M.S;Estudo do comportamento hidrodinâmico de uma nova proposta de configuração interna para reator UASB.Universidade Federal do Rio Grande do Sul,Porto Alegre, 2000

COMITEPCJ.GOV.BR ,Hidráulica e cinética de reatores cap.3. Curso de tratamento de esgoto

NOUR, E.A.A.; CANDELLO, F.P.; DOS SANTOS, E.M.R.;BARRETTO, A.S.;DOMINGUES, L.M.;Tratamento biológico de formaldeído: toxicidade residual monitorada por bioensaios com Daphnia similis.Universidade Estadual de Campinas, Campinas, 2014 